\title{
Cellulose hydrolysis catalysed by mesoporous activated carbons functionalized under mild conditions
}

\author{
F.-Z. Azar ${ }^{1}$ - M. A. Lillo-Ródenas ${ }^{1}$ (I) · M. C. Román-Martínez ${ }^{1}$ (I)
}

Received: 23 August 2019 / Accepted: 23 November 2019 / Published online: 30 November 2019

(C) Springer Nature Switzerland AG 2019

\begin{abstract}
The catalytic hydrolysis of cellulose allows the transformation of this sustainable and renewable raw material to obtain biofuels and high-added value chemicals. The process requires acidic catalysts, which should be preferably solid in order to make it greener and, thus, this work proposes the use of functionalized carbon materials for such an application. A mesoporous commercial carbon of trade name SA-30, abbreviated as SA in this work, has been chemically treated at room temperature to create acidic surface oxygen functional groups. The prepared carbon catalysts have been thoroughly characterized by $\mathrm{N}_{2}$ adsorption-desorption at $-196^{\circ} \mathrm{C}$, temperature programmed desorption and X-ray photoelectron spectroscopy. SAS carbon (prepared by treatment with a saturated solution of $\left(\mathrm{NH}_{4}\right)_{2} \mathrm{~S}_{2} \mathrm{O}_{8}$ in $1 \mathrm{M} \mathrm{H}_{2} \mathrm{SO}_{4}$ and named by adding $\mathrm{S}$ to the name of the original carbon) is the most effective of the studied catalysts. It allows achieving high cellulose conversion (about 61\%) and glucose selectivity. Thus, the low-cost functionalized carbons prepared at mild conditions are effective and promising catalysts for the transformation of cellulose into glucose.
\end{abstract}

Keywords Cellulose hydrolysis · Glucose · Carbon materials · Room temperature functionalization

\section{Introduction}

The conversion of biomass into fuels and chemicals implies the exploitation of a renewable feedstock and can contribute to reduce the world's dependence on fossil fuels. There are many studies devoted to promote the use of biomass with the purpose of achieving a suitable way to replace fossil fuels, contributing, as well, to mitigate the environmental damage caused by their use. An example of these studies can be found in references [1-5]. Nowadays requirements imply that the biomass selected for such a use must be non-edible and agricultural land should not be dedicated to biomass growing, to avoid interference with food production. Thus, mainly lignocellulosic biomass by-products from agricultural and industrial processes shall be used. Lignocellulosic biomass is constituted by the following three polymeric components: cellulose (C6 units (glucose) with 1-4 $\beta$-glycosidic bonds), hemicellulose (mainly C5 units (xylose)) and lignin (amorphous polymer with three phenyl propanolic monomers bound by $\mathrm{C}-\mathrm{C}$ and ether bonds) [5]. Cellulose, the most abundant component of lignocellulosic biomass, is considered a particularly attractive resource to obtain fuels and useful chemical products [6] and it is also frequently used as a model of lignocellulosic materials. Among the different processes for cellulose conversion into fine chemicals, pyrolysis, microwave cracking, fermentation and hydrolysis, the last one has shown to be very suitable to obtain important feedstock molecules like glucose or

Electronic supplementary material The online version of this article (https://doi.org/10.1007/s42452-019-1776-6) contains supplementary material, which is available to authorized users.

M. C. Román-Martínez, mcroman@ua.es | ${ }^{1}$ MCMA Group, Department of Inorganic Chemistry and Materials Institute, Faculty of Sciences, University of Alicante, Ap. 99, 03080 Alicante, Spain. 
hydroxymethylfurfural [7-9]. Glucose can be considered as the first molecule obtained from cellulose hydrolysis, and it is an important product that can be converted into a broad variety of high-added value chemicals (Scheme 1).

Compared with other methods, hydrolysis is, in general, less costly and more selective. However, as a consequence of the robust structure of cellulose due to the profusion of inter and intra-molecular hydrogen bonds, such a process constitutes a technical and scientific challenge. Cellulose hydrolysis is usually carried out by means of homogeneous catalysis, either by enzymatic reactions [10] or by acidic hydrolysis using mineral acids [7]. However, these techniques present important drawbacks like long reaction time, low catalyst recycling factor, corrosion, etc., and because of that, heterogeneous catalysis using solid acids (e.g., resins, metal oxides, zeolites) has become an interesting, and much "greener", alternative [11, 12].

Carbon materials have attracted a lot of attention in the field of heterogeneous catalysis. This is due to interesting and tuneable properties like morphology, porosity and surface chemistry, in addition to chemical stability in many liquid media and thermal stability in non-oxidising atmospheres. In fact, they have been frequently used as catalysts and catalysts supports [13]. The presence of Oxygen Functional Groups (OFG) on the carbon surface, particularly in the case of mesoporous carbons, seems to be beneficial for the adsorption of $\beta-1,4$ glucan chains, what can help to the cellulose network disintegration. The formation of hydrogen bonds with the glucan chains promotes the hydrolysis of the glycosidic bonds [14]. Examples of this use of carbon materials include the work of Shrotri et al. [15], who modified the carbon surface by air oxidation, but also added diluted $\mathrm{HCl}$ to the reaction media to increase the catalyst's activity, and the works of Hara et al., that used concentrated $\mathrm{H}_{2} \mathrm{SO}_{4}$ solution at high temperature to create not only OFG, but also sulfonic groups $[14,16,17]$.

The present work is focused on the preparation of carbon based catalysts for the hydrolysis of cellulose, using a commercial mesoporous activated carbon, with the purpose of developing an adequate surface chemistry by oxidation and sulfonation treatments carried out in liquid phase at room temperature. The main objective is to create the suitable amount and type of surface functionalities, especially acidic ones, while retaining the optimum desired textural properties.

The used oxidation method consists of a treatment with a saturated aqueous solution of $\left(\mathrm{NH}_{4}\right)_{2} \mathrm{~S}_{2} \mathrm{O}_{8}$ in $1 \mathrm{M} \mathrm{H}_{2} \mathrm{SO}_{4}$ at room temperature. It has been selected because, as indicated by Moreno-Castilla et al. [18, 19], it introduces strong acidic groups and, furthermore, it does not significantly modify the textural properties of the original activated carbon and, as indicated by Li et al [20], it is non-hazardous, non potentially explosive, economical and highly soluble in water. On the other hand, as sulphuric acid is frequently used to develop sulfonic groups on the carbon surface $[17,21,22]$, the carbon resulting after treatment with $1 \mathrm{M} \mathrm{H}_{2} \mathrm{SO}_{4}$ solution at room temperature (the one used in the ammonium persulfate treatment) has been also considered a potential catalyst. It should be pointed out that these conditions are clearly milder than those usually reported for such a way to create sulfonic groups (for example, concentrated $\mathrm{H}_{2} \mathrm{SO}_{4}$ at $373 \mathrm{~K}$ [22] and $10 \mathrm{M}$ $\mathrm{H}_{2} \mathrm{SO}_{4}$ at $373 \mathrm{~K}$ [21]).

The adopted surface modification strategies involve mild conditions and, thus, they can be regarded as lowcost methods. Detailed analysis of the surface chemistry has been performed to determine the specific surface functionalities that enhance cellulose hydrolysis and selectivity to glucose.
Scheme 1 High added-value chemicals from glucose
Bio-ethanol, aspartic acid, Hydroxypropionic acid, glutamic acid, malic acid

Sorbitol, mannitol, ethylene glycol, polyethylene glycol

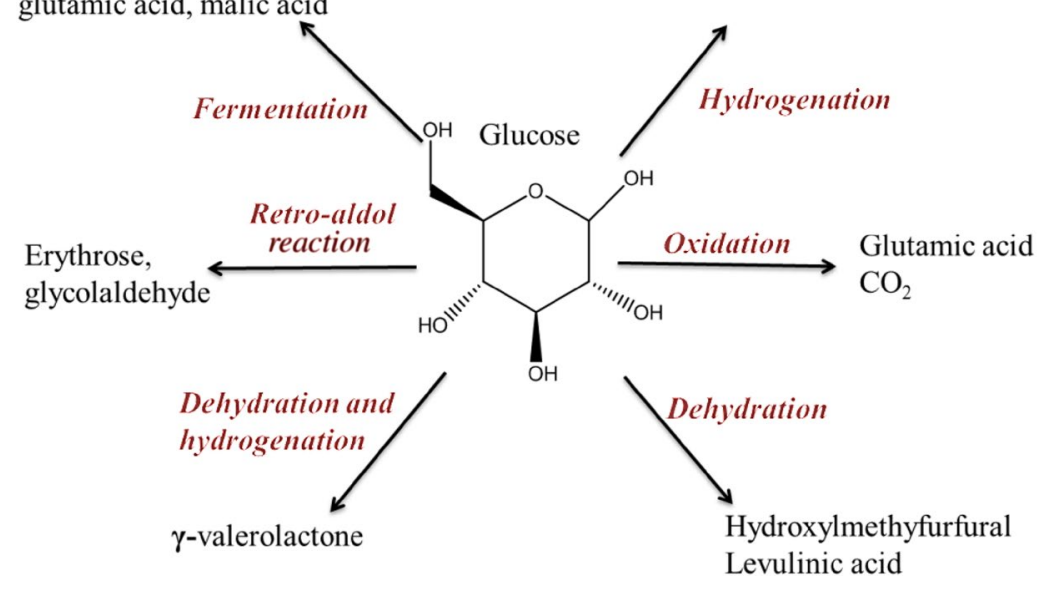

SN Applied Sciences 
Thus, in summary, this work focuses on the development of effective heterogeneous hydrolysis catalysts consisting on functionalized carbon materials, as they have properties scarcely exploited yet for this reaction (like a suitable porosity and a tuneable surface chemistry). The development of such catalysts is desired for the replacement of the commonly used liquid strong acids. This, together with the use of mild conditions for the catalysts preparation (with economic and environmental benefits), and the detailed characterization of the carbon-based catalysts, are the main scientific contributions of this work.

\section{Experimental}

\subsection{Materials}

The commercial activated carbon from MeadWestvaco (USA) named SA-30, which is produced by activation using $\mathrm{H}_{3} \mathrm{PO}_{4}$, has been selected to prepare the carbon catalyst because of its high surface area and mesopore volume [23]. The carbon, named SA in this work, was treated with the following chemical agents:

1. Saturated solution of $\left(\mathrm{NH}_{4}\right)_{2} \mathrm{~S}_{2} \mathrm{O}_{8}$ in aqueous $1 \mathrm{M} \mathrm{H}_{2} \mathrm{SO}_{4}$ (sample SAS)

2. $1 \mathrm{M} \mathrm{H}_{2} \mathrm{SO}_{4}$ aqueous solution (sample $\mathrm{SASu}$ ).

In both cases, the mixture carbon/solution (1 $\mathrm{g}$ activated carbon/ $10 \mathrm{ml}$ solution) was maintained under stirring for $24 \mathrm{~h}$ at room temperature. Afterwards, the treated carbons were filtered, and then washed several times with distilled water until the filtrate became neutral and sulfates were removed out (determined by $\mathrm{BaCl}_{2}$ testing).

The performance of the carbon catalysts was compared with that of the Amberlyst 15 resin (Sigma Aldrich), a known acidic solid [24, 25].

The commercial microcrystalline Avicel cellulose (99\% purity, Sigma Aldrich) was pre-treated by ball-milling in a planetary mill, with agate balls/cellulose weight ratio of 3 , at $500 \mathrm{rpm}$ for $7 \mathrm{~h}$ with reverse rotation every $60 \mathrm{~min}$ [26].

\subsection{Characterization}

The textural properties of SA, SAS and SASu carbon materials were determined by $\mathrm{N}_{2}$ adsorption-desorption at -196 ${ }^{\circ} \mathrm{C}$ using a Quantachrome Autosorb-6B equipment. The apparent $B E T$ surface area $\left(\mathrm{S}_{\mathrm{BET}}\right)$ and the total micropore volume $\left(\mathrm{V}_{\text {micro, }}\right.$ volume of pores with diameter lower than $2 \mathrm{~nm}$ ) were calculated using the BET and Dubinin-Radushkevich equations $[27,28]$, respectively. The mesopore volume $\left(V_{\text {meso }}\right.$, volume of pores with diameter between 2 and $20 \mathrm{~nm}$ ) was estimated as the difference between the amount of $\mathrm{N}_{2}$ adsorbed at $\mathrm{P} / \mathrm{P}_{0}=0.99$ and at $\mathrm{P} / \mathrm{P}_{0}=0.2$ and the total pore volume $\left(V_{\text {tot }}\right)$ was obtained from the volume of $\mathrm{N}_{2}$ adsorbed at $\mathrm{P} / \mathrm{P}_{0}=0.95[29,30]$. The mean pore size was determined by the equation $D=4 \times V_{\text {tot }} / S_{B E T}$ [28].

The surface chemistry of the carbon catalysts was analysed by temperature programmed desorption (TPD) $\left(20^{\circ} \mathrm{C} / \mathrm{min}\right.$ up to $900^{\circ} \mathrm{C}, 100 \mathrm{ml} / \mathrm{min}$ He flow) using a thermobalance (TA-SDT Q600) coupled to a mass spectrometer (Thermostar, Balzers). This enables the simultaneous record of weight loss, and $\mathrm{CO}_{2}$ and $\mathrm{CO}$ evolution. The surface chemistry of the carbon materials was also characterized by X-ray Photoelectron Spectroscopy (XPS, VG Microtech Multilab ESCA-3000 spectrometer). XPS spectra were obtained using a K-Alpha spectrometer (Thermo-Scientific), with a high resolution monochromator and the following specifications: Al anode (1486.6 eV) X-ray source, $5 \times 10^{-9}$ mbar analysis chamber pressure and detection in constant energy mode with pass energy of $200 \mathrm{eV}$ for the survey spectrum, and of $50 \mathrm{eV}$ for the sweep in each individual region. Data analysis was performed with the Origin peak fitting software.

Moreover, the amount of acidic sites was determined using a simplified Boehm titration method in which $0.1 \mathrm{~g}$ carbon were mixed with $20 \mathrm{ml}$ of a $0.05 \mathrm{M} \mathrm{NaOH}$ solution. Then, the mixture was treated in ultrasound bath for $1 \mathrm{~h}$ and, after filtration, the solution was titrated with $\mathrm{HCl} 0.05 \mathrm{M}$.

The carbon catalysts have been also analysed by TEM in order to characterize their microstructure. JEM-2010 transmission electron microscope from JEOL with an acceleration voltage of $200 \mathrm{kV}$ has been used for this purpose.

The crystallinity of the Avicel cellulose, before and after the milling treatment, was analysed by X-ray diffraction (XRD) using the Miniflex II Rigaku equipment $(30 \mathrm{kV} / 15 \mathrm{~mA})$ with $\mathrm{Cu}$ Ka radiation and a scanning rate of $2^{\circ} / \mathrm{min}$, in the $6-80^{\circ} 2 \theta$ range. The crystallinity index has been calculated as $\mathrm{Crl}(\%)=\left[\left(\mathrm{I}_{200}-\mathrm{I}_{\mathrm{am}}\right) / \mathrm{I}_{200}\right]^{* 100}$, where $\mathrm{I}_{200}$ and $\mathrm{I}_{\mathrm{am}}$ are the intensity of the peaks at $22.30^{\circ}$ and $18^{\circ}$, respectively [31].

\subsection{Catalytic tests}

The catalytic tests were performed in a $50 \mathrm{ml}$ stainless steel Parr reactor (Model 4792), lined with a Teflon container. The reaction conditions were chosen after a literature revision and are the following: $500 \mathrm{mg}$ cellulose, $125 \mathrm{mg}$ catalyst, $25 \mathrm{ml}$ distilled water, $190^{\circ} \mathrm{C}$ and $3 \mathrm{~h}$, under stirring. At the end of the experiment, the solid and liquid phases were separated by filtration. The liquid phase was analysed by high performance liquid chromatography (HPLC, 1200 infinity Agilent Technologies, column; Hi-Plex Ca (Duo), $300 \times 6.5 \mathrm{~mm}$ ) and the solid was dried and weighted to calculate the cellulose conversion. 
Conversion, product yield and selectivity were calculated according to the following expressions:
Material (Figure S1) and they show that SA and SASu samples have similar pore size distribution, while SAS

Conversion $=[1-($ weight of unreacted cellulose $/$ weight of charged cellulose $)] \times 100$

Yield of $A=[$ moles of $\mathrm{A} /$ moles of charged cellulose $] \times 100$

Selectivity to $A=[$ yield of $A /$ conversion $] \times 100$

\section{Results and discussion}

\subsection{Cellulose pretreatment}

Ball milling is an efficient physical pre-treatment to decrease the cellulose crystallinity, thus facilitating its hydrolysis [32]. Figure 1 shows the XRD results obtained for the original and milled Avicel cellulose, which reveal the important crystallinity decrease produced after the ball-milling treatment.

The calculated crystallinity index $(\mathrm{Cr})$ of the untreated cellulose (Fig. 1a) is $61 \%$, while the XRD profile of the ballmilled cellulose (Fig. 1b) does not allow determining the $\mathrm{Crl}$ because, as the material becomes quite amorphous, a clear $\mathrm{I}_{200}$ peak can not be distinguished. Therefore, it is evident that the ball-milling pretreatment greatly reduces the crystallinity of this microcrystalline cellulose.

\subsection{Catalysts textural properties}

Figure 2 shows the $\mathrm{N}_{2}$ adsorption-desorption isotherms at $-196{ }^{\circ} \mathrm{C}$ obtained for the three carbon materials used as catalysts. They are type IV isotherms according to the IUPAC classification [30], characteristic of mesoporous adsorbents. The relatively high adsorption at low relative pressure indicates that the samples have a significant micropore volume, and the steep slope indicates that their pore size distribution is wide. The pore size distribution graphs are presented as Supplementary

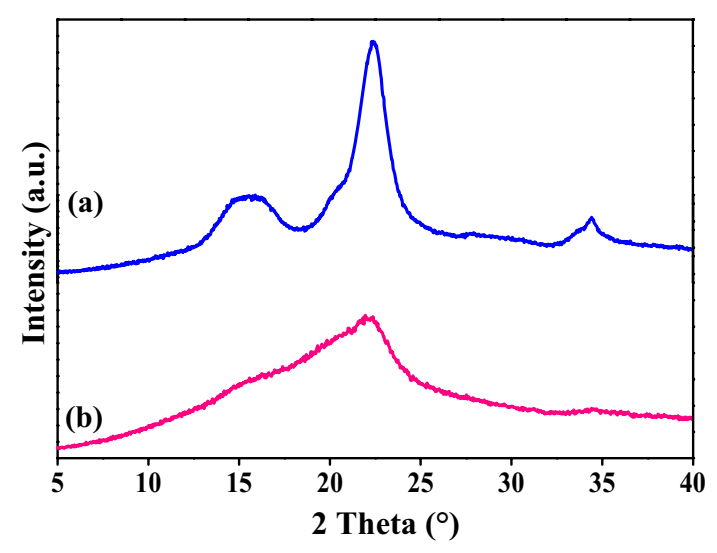

Fig. 1 XRD profiles of Avicel cellulose: (a) untreated, (b) ball-milled sample has also a wide pore size distribution, but with lower narrow micropore volume. The textural parameters, calculated from the $\mathrm{N}_{2}$ adsorption-desorption isotherms as indicated in the experimental section, are presented in Table 1.

The SA activated carbon presents high specific surface area and a well-developed porosity, both in the micro and mesopore ranges. The treatment with $1 \mathrm{M} \mathrm{H}_{2} \mathrm{SO}_{4}$ solution (sample SASu) produces only a slight modification of the porous structure. In contrast, the treatment of $\mathrm{SA}$ with the solution of $\left(\mathrm{NH}_{4}\right)_{2} \mathrm{~S}_{2} \mathrm{O}_{8}$ in $1 \mathrm{M} \mathrm{H}_{2} \mathrm{SO}_{4}$ (sample SAS) leads to a significant decrease of the adsorption capacity, which can be due either to destruction of pores, or to porosity blockage by the developed surface oxygen groups, as reported for other carbon materials submitted to a similar treatment [33].

In any case, the three carbon materials used in this work present well-developed mesoporosity and high surface area. As previously reported [34], mesoporosity is useful for the adsorption of $\beta-1,4$ glucan chains, which could then be broken on the carbon surface. The Amberlyst 15 resin has low surface area and total pore volume (about $40 \mathrm{~m}^{2} \mathrm{~g}^{-1}$ and $0.2 \mathrm{~cm}^{3} \mathrm{~g}^{-1}$, respectively) [24, 25], much lower than those of the carbon materials.

The micro/nanostructure of the carbon materials, as revealed by TEM, can be observed in Figure S2 (Supplementary Material). It can be seen that it is the expected one for an activated carbon in which the small carbon

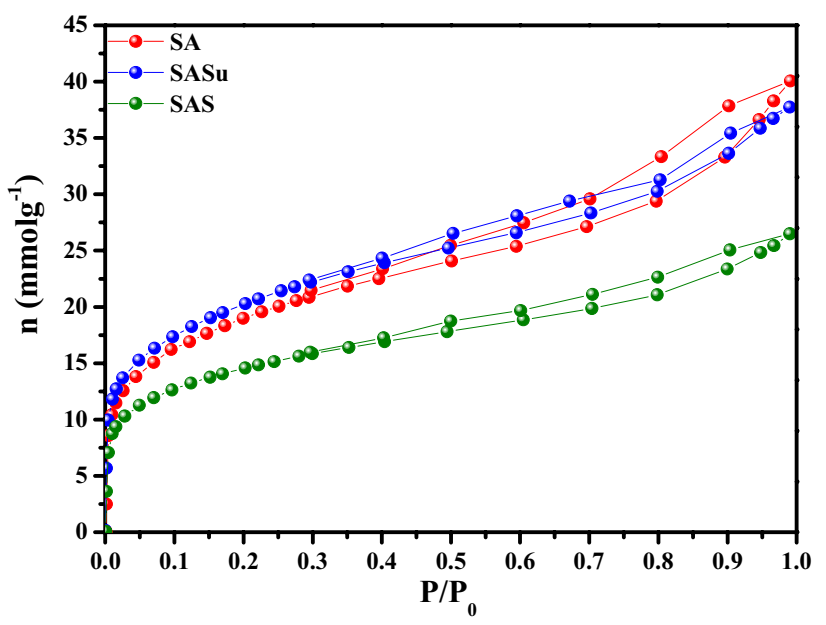

Fig. $2 \mathrm{~N}_{2}$ adsorption-desorption isotherms at $-196^{\circ} \mathrm{C}$ 
Table 1 Textural properties

\begin{tabular}{llllll}
\hline Sample & $\mathrm{S}_{\mathrm{BET}}\left(\mathrm{m}^{2} \mathrm{~g}^{-1}\right)$ & $\mathrm{V}_{\text {micro }}\left(\mathrm{cm}^{3} \mathrm{~g}^{-1}\right)$ & $\mathrm{V}_{\text {meso }}\left(\mathrm{cm}^{3} \mathrm{~g}^{-1}\right)$ & $\mathrm{V}_{\text {total }}\left(\mathrm{cm}^{3} \mathrm{~g}^{-1}\right)$ & $\begin{array}{l}\text { Mean } \\
\text { pore size } \\
(\mathrm{nm})\end{array}$ \\
\hline SA & 1464 & 0.74 & 0.73 & 1.40 & 3.83 \\
SASu & 1522 & 0.78 & 0.60 & 1.24 & 3.44 \\
SAS & 1274 & 0.56 & 0.48 & 0.99 & 3.11 \\
\hline
\end{tabular}

$S_{B E T} B E T$ surface area, $V_{\text {micro }}$ micropore volume, $V_{\text {meso }}$ mesopore volume, $V_{\text {total }}$ total pore volume (for details see the text)

(a)

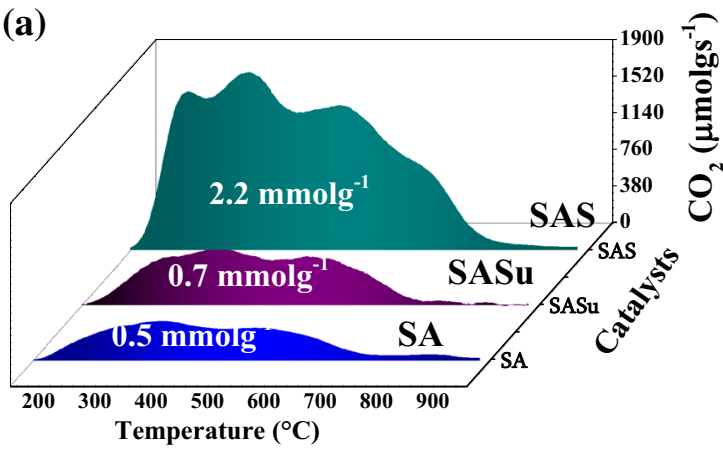

(b)

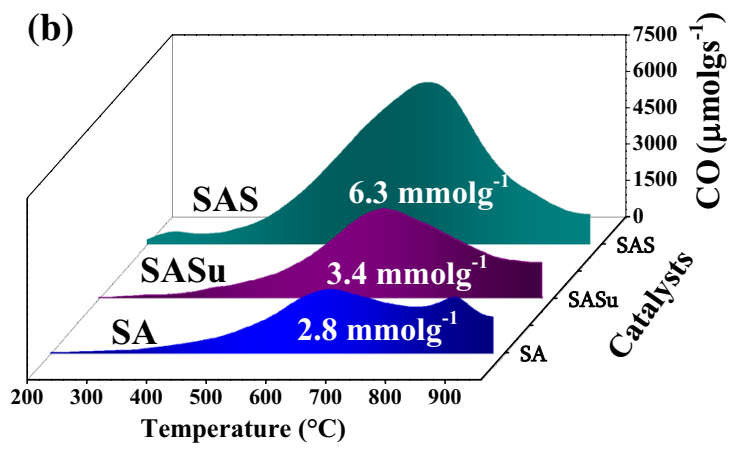

Fig. 3 TPD spectra of SA, SASu and SAS samples: $\mathbf{a} \mathrm{CO}_{2}$ evolution and $\mathbf{b} \mathrm{CO}$ evolution

platelets can be observed forming a microcrystalline structure. It must be mentioned that such a structure is not significantly modified by the chemical treatments performed.

\subsection{Catalysts surface chemistry}

Figure 3 shows the $\mathrm{CO}_{2}$ and $\mathrm{CO}$ evolution profiles obtained in the TPD experiments carried out with the three studied carbon materials. It can be observed that the treatment with $1 \mathrm{M} \mathrm{H}_{2} \mathrm{SO}_{4}$ leads to the creation of a moderated amount of oxygen functional groups (OFG) on the carbon surface (sample SASu) while, as expected, the oxidation treatment carried out to produce the SAS sample results in much higher development of surface OFG (be aware of the different scale of Fig. 3a and b). The total amount of $\mathrm{CO}_{2}$ and $\mathrm{CO}$ evolved in the TPD measurements, calculated as $\mathrm{CO}+\mathrm{CO}_{2}$, accounts $3.3,4.1$ and $8.5 \mathrm{mmol} \mathrm{g}^{-1}$ for carbons SA, SASu and SAS, respectively. The TG data associated to the TPD experiments (Figure S3, Supplementary Material) show that the mass loss is in agreement with the thermal removal of OFG (comparison of mass loss below $100^{\circ} \mathrm{C}$ indicates that SASu sample contained more humidity).

In order to perform a deeper characterization of the surface chemistry, the $\mathrm{CO}_{2}$ and $\mathrm{CO}$ evolution profiles shown in Fig. 3 were deconvoluted with the purpose of determining the amount of different types of OFG (deconvolution is shown in Figure S4 of the Supplementary Material (SM)). For this purpose, deconvolution was done using a multiple Gaussian function and each peak was centred at temperature values selected according to the literature $[20,35,36]$. The $\mathrm{CO}_{2}$ evolution peaks corresponding to the decomposition of strongly (SC) and weakly (WC) acidic carboxylic groups are centred in the $230-270^{\circ} \mathrm{C}$ and $360-380^{\circ} \mathrm{C}$ intervals, respectively. Thus, SC and WC are carboxylic groups that differ in their thermal stability and in the $\mathrm{pH}$ that they confer to an aqueous suspension [37]. The TPD peaks due to the decomposition of other functional groups are centred in the following temperature intervals: $\sim 520$ to $550^{\circ} \mathrm{C}$ - carboxylic anhydride groups (CA); 650 to $670{ }^{\circ} \mathrm{C}$-lactone groups (LN) at, $\sim 650$ to $700{ }^{\circ} \mathrm{C}$-phenol type groups $(\mathrm{PH})$ and $750-943^{\circ} \mathrm{C}$ - carbonyl and quinone groups (CQ). These temperature intervals reveal that some OFG can decompose showing overlapped $\mathrm{CO}_{2}$ and CO desorption peaks.

It should be noted that two low temperature $\mathrm{CO}$ peaks (labelled as $\mathrm{CO} 1$ and $\mathrm{CO} 2$ ) appear in the fitting of the $\mathrm{CO}$ evolution profiles. They are centred at temperatures similar to those at which the peaks corresponding to the decomposition of SC and WC carboxylic groups are located. This phenomenon is also reported in literature. Figueiredo and co-workers attributed these peaks to the reaction between $\mathrm{CO}_{2}$ and the carbon surface [38], while Moreno-Castilla et al. consider that the low temperature $\mathrm{CO}$ probably comes from carbonyl groups that come from the decomposition of a-substituted ketones and aldehydes [18].

In the case of SA carbon, $\mathrm{CO}_{2}$ and $\mathrm{CO}$ desorption at $\sim 870^{\circ} \mathrm{C}$ (see Fig. 3 and Figure S4) has been explained as a consequence of surface reactions of trace phosphoric 
groups remaining from the activation treatment with $\mathrm{H}_{3} \mathrm{PO}_{4}[39,40]$. The absence of such features in the TPD spectra of SASu and SAS samples would indicate that phosphoric groups were mostly eliminated by the treatments with acidic solutions carried out to obtain them from the original SA carbon.

The amount of each type of OFG determined from the areas of the deconvoluted TPD profiles (excluding those related to phosphoric acid in carbon $\mathrm{SA}$ ) is presented in Table 2. It can be observed that in the original activated carbon, the most abundant OFG are phenol-type groups, followed by carbonyl and quinone groups. The treatment with $1 \mathrm{M} \mathrm{H}_{2} \mathrm{SO}_{4}$ solution leads to the development of all OFG types, being the increase of strongly acidic carboxylic groups the most pronounced. The treatment with the saturated solution of $\left(\mathrm{NH}_{4}\right)_{2} \mathrm{~S}_{2} \mathrm{O}_{8}$ in $1 \mathrm{M} \mathrm{H}_{2} \mathrm{SO}_{4}$ produces a noticeable increase in the total amount of OFG, which corresponds to the creation of all types of groups. It can be underlined that, compared to SASu, SAS carbon contains less carbonyl-quinone groups (Table 2).

The three samples contain a large amount of acidic OFG (calculated as the sum of SC, WC, CA, PH and LN) and the order regarding the OFG content is $\mathrm{SA}<\mathrm{SASu}<<\mathrm{SAS}$.

The acidity of the carbon materials determined by titration (expressed as mmol of acidic sites per gram of carbon, Table 2) follows the same trend, although the differences between samples are less pronounced.

The amount of acidic OFG determined by deconvolution of the TPD spectra has been plotted versus the amount of acidic sites determined by titration, and a linear correlation has been found (Fig. S5, Supplementary Material). However, the difference between the total amount of acidic oxygen groups determined from TPD data and the acidity determined by titration is relatively large. This point could be explained considering that not all the surface functional groups have the same acidity. Thus, titration is the result of an average measurement of groups with different acidity and basicity.
It can be pointed out that the acidity of carbon SAS ( $4.08 \mathrm{mmol} \mathrm{g}^{-1}$ determined by titration) is comparable to the acidity of Amberlyst 15 resin $\left(4.7 \mathrm{mmol} \mathrm{g}^{-1}\right)$ [24]. This strong acidity is expected to enhance the catalytic activity in the hydrolysis of cellulose $[14,41]$.

The surface chemistry of the carbon materials has been also characterized by means of XPS. Figure 4 shows the O1s XPS spectra of the three studied samples.

Deconvolution of the O1s spectra (Fig. 4) based on the binding energy (B.E.) assignments found in the literature $[25,42,43]$ shows peaks centred at the following B.E. values (in eV): (1) $530.7 \pm 0.2$, assigned to $C=O$ bond in quinone groups, (2) $531.8 \pm 0.2$, related to oxygen in $\mathrm{O}=\mathrm{C}$ or $-\mathrm{OH}$ structures of carbonyl or anhydrides and hydroxyl groups, (3) $533.3 \pm 0.2$, attributed to phenol type groups

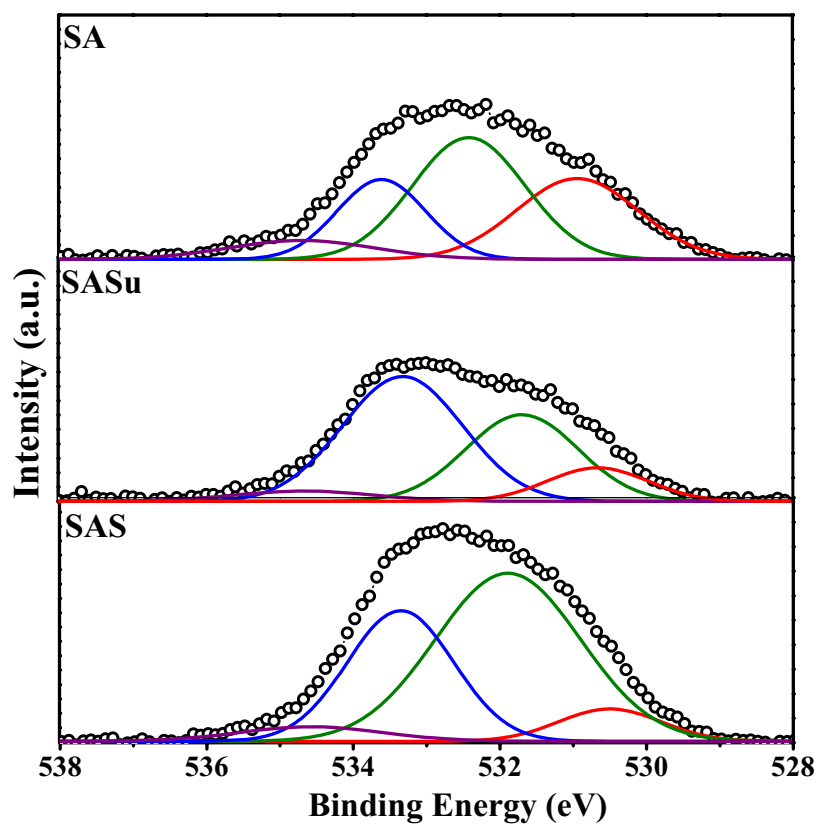

Fig. 4 O 1s XPS data of SA, SASu and SAS

Table 2 Distribution of OFG determined by deconvolution of the TPD profiles and amount of acidic sites measured by titration

\begin{tabular}{|c|c|c|c|c|c|c|c|c|c|}
\hline \multirow[t]{2}{*}{ Sample } & \multicolumn{6}{|c|}{ OFG $\left(\mathrm{mmolg}^{-1}\right)$} & \multirow[b]{2}{*}{$\begin{array}{c}\text { Total } \\
\mathrm{OFG}^{[\mathrm{a}]} \\
\left(\mathrm{mmolg}^{-1}\right)\end{array}$} & \multirow[b]{2}{*}{$\begin{array}{c}\text { Acidic } \\
\mathrm{OFG}^{[\mathrm{b}]} \\
\left(\mathrm{mmolg}^{-1}\right)\end{array}$} & \multirow[b]{2}{*}{$\begin{array}{c}\text { Acidic } \\
\text { sites }^{[c]} \\
\left(\mathrm{mmolg}^{-1}\right.\end{array}$} \\
\hline & $\mathrm{SC}$ & WC & $\mathrm{CA}$ & $\mathrm{PH}$ & LN & $\begin{array}{c}\text { CQ } \\
0\end{array}$ & & & \\
\hline SA & 0.06 & 0.18 & 0.18 & 1.02 & 0.04 & 0.85 & 2.33 & 1.48 & 3.33 \\
\hline SASu & 0.11 & 0.25 & 0.25 & 1.50 & 0.06 & 1.33 & 3.50 & 2.17 & 3.44 \\
\hline SAS & 0.27 & 0.82 & 0.93 & 3.40 & 0.22 & 1.16 & 6.80 & 5.64 & 4.08 \\
\hline
\end{tabular}

${ }^{\text {a }}$ Sum of all identified OFG

${ }^{\text {bS }}$ um of SC, WC, CA, PH and LN groups

${ }^{\mathrm{C}}$ Measured by titration 
Table 3 O1s XPS data: B.E. $(\mathrm{eV})$, species identification and quantification (at\%)

\begin{tabular}{|c|c|c|c|c|c|}
\hline Element & \multicolumn{5}{|c|}{ O 1s (at. \%) } \\
\cline { 1 - 4 } Species & $\mathbf{1}$ & $\mathbf{2}$ & $\mathbf{3}$ & $\mathbf{4}$ & \\
\cline { 1 - 4 } B.E. (eV) & 530.7 & 531.7 & 533.3 & 534.6 & $\begin{array}{c}\text { Acidic } \\
\text { OFG [a] }\end{array}$ \\
\cline { 1 - 3 } Formula & $\mathrm{C}=\mathrm{O}$ & $\begin{array}{c}\mathrm{O}=\mathrm{C} \text { or } \\
-\mathrm{OH}\end{array}$ & $\mathrm{C}-\mathrm{OH}$ & $\mathrm{C}=\mathrm{OOH}$ & 6.2 \\
\hline Sample & 2.6 & 3.6 & 1.9 & 0.7 & 5.9 \\
\hline SASu & 2.9 & 4.5 & 0.4 & 1.0 & 12.5 \\
\hline SAS & 1.0 & 7.5 & 4.3 & 0.6 & \\
\hline
\end{tabular}

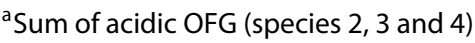

and (4) $534.6 \pm 0.2$, assigned to carboxylic groups. Table 3 shows the quantification of the $01 \mathrm{~s}$ spectra in atomic $\mathrm{O}$ percentage (at\%) in any of the mentioned oxygen containing surface functionalities.

The contribution of acidic OFG has been calculated assuming that species 2 to 4 (see Table 3 ) are related with anhydrides and hydroxyl, phenol, and carboxylic acid groups. It can be observed that both, the total amount of oxygen groups and the amount of acidic OFG determined this way, is similar for SA and SASu samples, and clearly higher for SAS.

The C $1 \mathrm{~s}$ spectra (presented in Figure S6, Supplementary Material) show, apart from the peak centred at about $284.5 \pm 0.1 \mathrm{eV}$ due to graphitic $\mathrm{C}=\mathrm{C}$, other less intense peaks appearing at $286.0 \pm 0.1 \mathrm{eV}, 286.7 \pm 0.1 \mathrm{eV}$ and $287.5 \pm 0.3 \mathrm{eV}$, which can be attributed to $\mathrm{C}-\mathrm{O}$ in ether or phenol groups, to quinone or carbonyl groups $(\mathrm{C}=\mathrm{O})$, and to carboxylic or carboxylic anhydride groups, respectively. Quantification of the C1s spectra has not been included, as it will be not precise enough because the intensity of the $\mathrm{C} 1 \mathrm{~s}$ signals due to OFG is low compared to the main peak due to $C=C$ bonds (see Figure S6).

The S $2 p$ XPS spectra of samples SASu and SAS, although with a lot of noise, show a peak located at about $168.1 \mathrm{eV}$ attributed to $\mathrm{S}$ in $-\mathrm{SO}_{3} \mathrm{H}$ groups [44]. This means that sulphur is present in these two samples, although the amount of this element is very low. In fact, the determination of sulphur by elemental analysis shows that the weight concentration of this element in both samples is about $0.1 \%$. Figure $S 7$ in Supplementary Material shows the S $2 p$ XPS spectra of the SAS catalyst before and after the reaction. The profiles obtained are similar, which indicates that the $-\mathrm{SO}_{3} \mathrm{H}$ groups have not been leached during reaction.

As in the case of the TPD analysis, acidic OFG evaluated by XPS are predominant in all samples (more than $75 \%$ of oxygen atoms are present in acidic groups). This is an interesting property of these carbon materials as the interaction between cellulose $\beta$-1,4-glucan chains and acidic OFG on the carbon surface is supposed to favour the breakage of the cellulose network, leading to higher catalytic activity [14].

\subsection{Catalytic performance}

The hydrolysis of cellulose with the four tested catalysts has led, mainly, to the formation of glucose and hydroxymethylfurfural (HMF). As reported in the literature, the reaction starts with a proton from the acid catalyst interacting with the glycosidic oxygen atoms that link two sugar units, forming a conjugated acid. After addition of water, free sugar and a proton are liberated, and further rehydratation and hydrolysis of glucose yields $\operatorname{HMF}[7,45]$.

The obtained values of cellulose conversion and product selectivity are shown in Fig. 5 .

Using the original SA carbon, cellulose conversion significantly increases compared to the blank test $(56 \%$ vs. $35 \%$ conversion), leading as well to a higher selectivity to glucose. This means that this activated carbon is a good catalyst for cellulose hydrolysis. After surface functionalization (samples SASu and SAS), the carbon catalysts

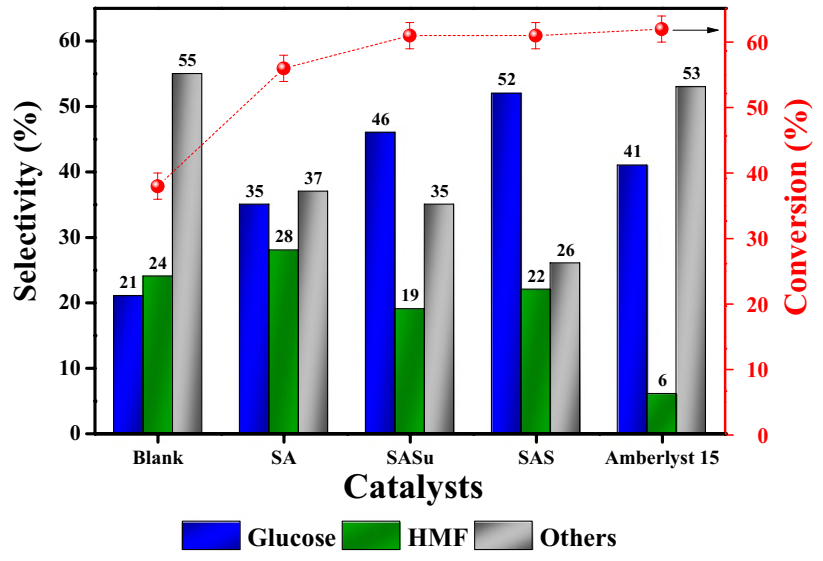

Fig. 5 Cellulose conversion (red points) and products selectivity (HMF: Hydroxymethylfurfural) $(500 \mathrm{mg}$ cellulose, $125 \mathrm{mg}$ catalyst, $25 \mathrm{ml}$ distilled water, $190^{\circ} \mathrm{C}$ and $3 \mathrm{~h}$ ) 
improve their catalytic performance, leading to $60 \%$ cellulose conversion and glucose selectivity close to $50 \%$. In contrast, the commercial Amberlyst 15 resin exhibits a good cellulose conversion (62\%), but a lower selectivity to glucose (41\%). Besides, as in the case of the blank experiment, the Amberlyst 15 resin renders a high proportion of other products, each of them in low concentration, that have not been completely identified (furfural, ethylene glycol, polyethylenglycol and levulinic acid can be some of these products), meaning that using this catalyst, the main hydrolysis products (glucose and HMF) are highly degraded.

Regarding the effectiveness of the studied catalysts in terms of glucose yield, the obtained results with the carbon catalysts are $17 \%, 28 \%$ and $32 \%$ for SA, SASu and SAS, respectively, while $25 \%$ is obtained with Amberlyst 15. The glucose yield of the oxidized carbon materials is higher than that of Amberlyst 15 because they afford a similar cellulose conversion and are clearly more selective to glucose. Thus, the oxidized carbon materials are more effective catalysts than the commercial resin Amberlyst 15. On the other hand, they are more active than the SA original carbon, in spite of having lower pore volume and, in the case of SAS, also lower surface area, what can be attributed to the increase in the amount of acidic surface groups. However, the extensive creation of acidic OFG by the oxidation treatment with the $\left(\mathrm{NH}_{4}\right)_{2} \mathrm{~S}_{2} \mathrm{O}_{4}$ solution in $1 \mathrm{M} \mathrm{H}_{2} \mathrm{SO}_{4}$ (SAS sample) does not lead to a further increase of the cellulose conversion respect to the behaviour of the SASu catalyst, and the increase in glucose selectivity is much lower than the increase in the amount of OFG. The increase in selectivity is more pronounced from SA to SASu than from SASu to SAS. This can be explained either by a limit in the positive effect of acidic OFG, by the lower surface area and pore volume, or by a combination of these two reasons. The good catalytic performance of SASu and SAS carbons for cellulose hydrolysis can be also related with the presence of sulfonic groups (detected by XPS). The stability of those groups was proved by their presence in the SAS catalyst surface before and after reaction (Fig. S4, SM).
The obtained results mean that the oxidized carbon materials show a good catalytic performance. However, to support this idea, it is necessary to compare the obtained data with recent results on the topic reported in the literature. Nevertheless, such a comparison is usually not straightforward because the reaction conditions are different, and sometimes the way to express the catalytic activity is different as well. In any case, some reported data have been collected in Table 4, indicating the differences in the operation conditions. The reported data correspond to the use of carbon materials as catalysts, without acid addition, and water as solvent. Explanations and comments on the information presented in the table are given below.

BA-475, an oxidized (air, $475^{\circ} \mathrm{C}, 3 \mathrm{~h}$ ) high surface area $\left(1100 \mathrm{~m}^{2} \mathrm{~g}^{-1}\right)$ commercial activated carbon was used as catalyst in a mix-milling process with microcrystalline cellulose (entry 1 [15]) and, although a high cellulose conversion was obtained (with the advantages of high S/C ratio and low reaction time), the glucose yield is moderate, meaning that many by-products have been formed. Besides, the oxidation treatment led to $54 \%$ burn-off, which implies a significant loss of solid. Huang et al. (entry 2 [46]), used a graphene oxide prepared from graphite by the harsh Hummers method, and then submitted to a sulfonation treatment (with $98 \%$ sulfuric acid). The results are poor using water as solvent (data shown in the table), but they noticeably improve when the solvent is $1 / 10$ (vol/ vol) mixture of water and N-dimethylacetamide. Gan et al. (entry 3 [47]) use a lignin derived solid acid (LDSA) sulfonated in concentrated sulfuric acid with quite low $\mathrm{S} / \mathrm{C}$ ratio (high amount of catalyst). The results are expressed as yield to total reducing sugars (TRS), and because of that, it is not possible to make a proper comparison of glucose yield. Data of entry 4 [48] correspond to a solid acid catalyst prepared by the co-carbonization of cellulose and PVC (as a way of reusing plastic wastes) and to cellulose pretreated in highly concentrated phosphoric acid. The S/C used was low and instead of glucose yield, yield to TRS is presented. In the work of Li et al. (entry 5 [49]) the carbon catalyst is based on coal tar pitch mesocarbon mesobeads (MCMB) submitted to a sulfonation treatment
Table 4 Summary of reported results for several carbon based catalysts in hydrolysis reaction conditions similar to those used in the present work

\begin{tabular}{llllllll}
\hline Entry & Catalyst name & $\mathrm{S} / \mathrm{C}^{\mathrm{a}}$ & $\mathrm{T}\left({ }^{\circ} \mathrm{C}\right)$ & $\mathrm{T}(\mathrm{h})$ & $\mathrm{X}_{\text {cellulose }}(\%)$ & $\mathrm{Y}_{\text {glucose }}(\%)$ & References \\
\hline 1 & $\mathrm{ACBA}-475$ & 6.5 & 180 & 0.3 & 96 & 27 & {$[15]$} \\
2 & ${\mathrm{GO}-\mathrm{SO}_{3} \mathrm{H}}$ & 1 & 130 & 8 & - & 1.4 & {$[46]$} \\
3 & $\mathrm{LDSA}$ & 0.25 & 180 & 4 & - & $46-\mathrm{TRS}$ & {$[47]$} \\
4 & $\mathrm{MPCSA}$ & 0.5 & 150 & 6 & - & $58-\mathrm{TRS}$ & {$[48]$} \\
5 & $\mathrm{R}-\mathrm{MCMB}-\mathrm{SO}_{3} \mathrm{H}$ & 0.2 & 140 & 4 & 68 & $66-\mathrm{TRS}$ & {$[49]$} \\
6 & $\mathrm{G}-\mathrm{TSOH}$ & 1 & 170 & 12 & 31 & 16 & {$[50]$} \\
7 & $\mathrm{SAS}$ & 4 & 190 & 3 & 60 & 32 & This work \\
\hline
\end{tabular}

${ }^{a}$ Substrate/catalyst ratio 
in concentrated sulfuric acid. Cellulose was previously chemically treated, the $S / C$ is very low and the activity results are also presented as yield to TRS. Finally, the work of Chen et al. (entry 6 [50]) reports the behaviour of several carbon materials prepared from glucose by hydrothermal synthesis and submitted to different treatments. The one indicated in the table shows the best behaviour in terms of glucose yield among those studied.

The comparison with literature results shows that the carbon catalysts prepared in the present work, particularly SAS, can be considered among the best ones because they lead to a high cellulose conversion and good glucose yield, using water as solvent, a relatively high $\mathrm{S} / \mathrm{C}$ ratio and short reaction time, although the reaction temperature is somewhat higher. It is important to point out that the SAS carbon leads to the lowest amount of by-products, being $74 \%$ the global selectivity to interesting products (glucose and HMF). Besides, the carbon catalysts used in this work have been obtained from a commercial activated carbon and the treatments performed to modify the surface chemistry can be considered mild, in contrast with the more complex and costly treatments reported in most publications.

In summary, the low-cost (mild conditions) modified carbon materials developed in this work combine the required acidity and suitable textural properties, and because of that, they perform better than the Amberlyst 15 resin and some other carbon materials reported in the literature. Amberlyst 15 has low surface area and porosity and a high acidity, which promotes side reactions, converting cellulose or glucose to other by-products. Also, the carbon materials used in this work can be considered advantageous when compared to the resin and other carbon materials because of their lower price or easier (and cheaper) preparative procedures.

\section{Conclusions}

Low-cost solid acid catalysts for cellulose hydrolysis have been prepared by the modification under mild conditions of the surface chemistry of a commercial mesoporous activated carbon. The three studied carbon catalysts are active for cellulose conversion, and the two oxidized ones show a high selectivity to glucose. Because of that, they show a better performance (higher glucose yield and less by-products) than the commercial Amberlyst 15 resin. SAS carbon (prepared by treatment with a saturated solution of $\left(\mathrm{NH}_{4}\right)_{2} \mathrm{~S}_{2} \mathrm{O}_{8}$ in $\left.1 \mathrm{M} \mathrm{H}_{2} \mathrm{SO}_{4}\right)$ is the most effective of the studied catalysts, leading to $61 \%$ cellulose conversion and $52 \%$ selectivity to glucose. This good behaviour can be attributed to a proper combination of high OFG amount and suitable porosity. Acidic OFG were found to play a key role in improving the catalytic performance of carbon materials for cellulose hydrolysis and selectivity to glucose, but the presence of a small amount of sulfonic groups also seems to be relevant.

Acknowledgements The authors thank Ministerio de Ciencia, Innovación y Universidades (RTI2018-095291-B-I00), GV/FEDER (PROMETEOII/2014/010) and University of Alicante (VIGROB-136) for financial support. F.-Z. Azar thanks the AECID (research scholarship for development (2015/2016)) and University of Alicante (cooperation programs for development) for financial support.

\section{Compliance with ethical standards}

Conflict of interest On behalf of all authors, the corresponding author states that there is no conflict of interest.

\section{References}

1. Serrano-Ruiz JC, Dumesic JA (2011) Catalytic routes for the conversion of biomass into liquid hydrocarbon transportation fuels. Energy Environ Sci 4:83-99. https://doi.org/10.1039/COEE0 0436G

2. Kunkes EL, Simonetti DA, West RM et al (2008) Catalytic conversion of biomass to monofunctional hydrocarbons and targeted liquid-fuel classes. Science 322:417-421. https://doi. org/10.1126/science.1159210

3. Stöcker M (2008) Biofuels and biomass-to-liquid fuels in the biorefinery: catalytic conversion of lignocellulosic biomass using porous materials. Angew Chemie Int Ed 47:9200-9211. https:// doi.org/10.1002/anie. 200801476

4. Kamm B, Grüber PR, Kamm M (2015) Biorefineries-industrial processes and products. In: Ullmann's encyclopedya of industrial chemistry. Wiley-VCH Verlag GmbH \& Co. KGaA, Weinheim. https://doi.org/10.1002/14356007.I04_I01.pub2

5. Zhou C, Xia X, Lin C et al (2011) Catalytic conversion of lignocellulosic biomass to fine chemicals and fuels. Chem Soc Rev 40:5588-5617. https://doi.org/10.1039/c1cs15124j

6. Van De Vyver S, Geboers J, Jacobs PA, Sels BF (2011) Recent advances in the catalytic conversion of cellulose. ChemCatChem 3:82-94. https://doi.org/10.1002/cctc.201000302

7. Fan L, Gharpuray MM, Lee Y-H (1987) Cellulose hydrolysis. Springer, Berlin

8. Liu M, Jia S, Gong Y et al (2013) Effective hydrolysis of cellulose into glucose over sulfonated sugar-derived carbon in an ionic liquid. Ind Eng Chem Res 52:8167-8173. https://doi. org/10.1021/ie400571e

9. Rinaldi R, Schüth F (2009) Acid hydrolysis of cellulose as the entry point into biorefinery schemes. Chemsuschem 2:10961107. https://doi.org/10.1002/cssc.200900188

10. Zhang YHP, Lynd LR (2004) Toward an aggregated understanding of enzymatic hydrolysis of cellulose: noncomplexed cellulase systems. Biotechnol Bioeng 88:797-824. https://doi. org/10.1002/bit.20282

11. Rinaldi R, Schüth F (2009) Design of solid catalysts for the conversion of biomass. Energy Environ Sci 2:610-626. https://doi. org/10.1039/b902668a

12. Aspromonte SG, Romero A, Boix AV, Alonso E (2019) Hydrolysis of cellulose to glucose by supercritical water and silver 
mesoporous zeolite catalysts. Cellulose 26:2471-2485. https:// doi.org/10.1007/s10570-018-2221-5

13. Serp P, Figueiredo JL (2009) Carbon materials for catalysis. Wiley, Hoboken

14. Kitano M, Yamaguchi D, Suganuma S et al (2009) Adsorptionenhanced hydrolysis of $/ \beta-1,4$-glucan on graphene-based amorphous carbon bearing $\mathrm{SO}_{3} \mathrm{H}, \mathrm{COOH}$, and $\mathrm{OH}$ groups. Langmuir 25:5068-5075. https://doi.org/10.1021/la8040506

15. Shrotri A, Kobayashi H, Fukuoka A (2016) Air oxidation of activated carbon to synthesize a biomimetic catalyst for hydrolysis of cellulose. Chemsuschem 9:1299-1303. https://doi. org/10.1002/cssc.201600279

16. Suganuma S, Nakajima K, Kitano M et al (2008) Hydrolysis of cellulose by amorphous carbon bearing $\mathrm{SO}_{3} \mathrm{H}, \mathrm{COOH}$, and $\mathrm{OH}$ groups. J Am Chem Soc 130:12787-12793. https://doi. org/10.1021/ja803983h

17. Nakajima $\mathrm{K}$, Hara $\mathrm{M}$ (2012) Amorphous carbon with $\mathrm{SO}_{3} \mathrm{H}$ groups as a solid Brønsted acid catalyst. ACS Catal 2:1296-1304. https ://doi.org/10.1021/cs300103k

18. Moreno-Castilla C, Carrasco-Marín F, Mueden A (1997) The creation of acid carbon surfaces by treatment with $\left(\mathrm{NH}_{4}\right)_{2} \mathrm{~S}_{2} \mathrm{O}_{8}$. Carbon 35:1619-1626. https://doi.org/10.1016/S0008 $-6223(97) 00121-8$

19. Moreno-Castilla C, Ferro-Garcia MA, Joly JP et al (1995) Activated carbon surface modifications by nitric acid, hydrogen peroxide, and ammonium peroxydisulfate treatments. Langmuir 11:43864392. https://doi.org/10.1021/la00011a035

20. Li N, Ma X, Zha Q et al (2011) Maximizing the number of oxygen-containing functional groups on activated carbon by using ammonium persulfate and improving the temperatureprogrammed desorption characterization of carbon surface chemistry. Carbon 49:5002-5013. https://doi.org/10.1016/j. carbon.2011.07.015

21. Foo GS, Van Pelt AH, Krötschel D et al (2015) Hydrolysis of cellobiose over selective and stable sulfonated activated carbon catalysts. ACS Sustain Chem Eng 3:1934-1942. https://doi. org/10.1021/acssuschemeng.5b00530

22. Fraile JM, García-Bordejé E, Pires E, Roldán L (2014) New insights into the strength and accessibility of acid sites of sulfonated hydrothermal carbon. Carbon 77:1157-1167. https://doi. org/10.1016/j.carbon.2014.06.059

23. Marco-Lozar JP, Cazorla-Amorós D, Linares-Solano A (2007) A new strategy for germanium adsorption on activated carbon by complex formation. Carbon 45:2519-2528. https://doi. org/10.1016/j.carbon.2007.08.020

24. Kunin R, Meitzner E, Oline J (1962) Characterization of Amberlyst 15. IEC Prod Res Dev 1:140-144

25. Siril PF, Cross HE, Brown DR (2008) New polystyrene sulfonic acid resin catalysts with enhanced acidic and catalytic properties. J Mol Catal A Chem 279:63-68. https://doi.org/10.1016/j.molca ta.2007.10.001

26. Adsuar-García MD (2017) Catalizadores bifuncionales para la hidrogenación hidrolítica de la celulosa. Ph.D. thesis, University of Alicante

27. Gregg SJ, Sing KSW (1999) Adsorption, surface area and porosity. Academic Press, New York

28. Rouquerol F, Rouquerol J, Sing K (1999) Adsorption by powders and porous solids. Principles, methods and applications, 1st edn. Academia Press, San Diego

29. Rodriguez-Reinoso F, Linares-Solano A (1989) Chemistry and physics of carbon, vol 21. Marcel Dekker Inc, New York

30. Thommes M, Kaneko K, Neimark AV et al (2015) Physisorption of gases, with special reference to the evaluation of surface area and pore size distribution (IUPAC Technical Report). Pure Appl Chem 87:1051-1069
31. Das K, Ray D, Bandyopadhyay NR, Sengupta S (2010) Study of the properties of microcrystalline cellulose particles from different renewable resources by XRD, FTIR, nanoindentation, TGA and SEM. J Polym Environ 18:355-363

32. Avolio R, Bonadies I, Capitani D et al (2012) A multitechnique approach to assess the effect of ball milling on cellulose. Carbohydr Polym 87:265-273. https://doi.org/10.1016/j.carbp ol.2011.07.047

33. Rufete-Beneite M, Román-Martínez MC, Linares-Solano A (2014) Insight into the immobilization of ionic liquids on porous carbons. Carbon 77:947-957. https://doi.org/10.1016/j.carbo n.2014.06.009

34. Chung P-W, Charmot A, Click T et al (2015) Importance of internal porosity for glucan adsorption in mesoporous carbon materials. Langmuir 31:7288-7295. https://doi.org/10.1021/acs. langmuir.5b01115

35. Figueiredo JL, Pereira MFR, Freitas MMA, Órfão JJM (1999) Modification of the surface chemistry of activated carbons. Carbon 37:1379-1389. https://doi.org/10.1016/S0008-6223(98)00333-9

36. Domingo-García M, López Garzón FJ, Pérez-Mendoza MJ (2002) On the characterization of chemical surface groups of carbon materials. J Colloid Interface Sci 248:116-122. https://doi. org/10.1006/jcis.2001.8207

37. Boehm H (2002) Surface oxides on carbon and their analysis: a critical assessment. Carbon 40:145-149. https://doi. org/10.1016/S0008-6223(01)00165-8

38. Figueiredo JL, Pereira MFR, Freitas MMA, Órfão JJM (2007) Characterization of active sites on carbon catalysts. Ind Eng Chem Res 46:4110-4115. https://doi.org/10.1021/ie061071v

39. Li Y, Zhang $X$, Yang $\mathrm{R}$ et al (2015) The role of $\mathrm{H}_{3} \mathrm{PO}_{4}$ in the preparation of activated carbon from $\mathrm{NaOH}$-treated rice husk residue. RSC Adv 5:32626-32636. https://doi.org/10.1039/C5RA04634C

40. Valero-Romero MJ, García-Mateos FJ, Rodríguez-Mirasol J, Cordero T (2017) Role of surface phosphorus complexes on the oxidation of porous carbons. Fuel Process Technol 157:116-126. https://doi.org/10.1016/j.fuproc.2016.11.014

41. Huang Y-B, Fu Y (2013) Hydrolysis of cellulose to glucose by solid acid catalysts. Green Chem 15:1095-1111. https://doi. org/10.1039/C3GC40136G

42. Oh YJ, Yoo JJ, II Kim Y et al (2014) Oxygen functional groups and electrochemical capacitive behavior of incompletely reduced graphene oxides as a thin-film electrode of supercapacitor. Electrochim Acta 116:118-128. https://doi.org/10.1016/j.elect acta.2013.11.040

43. Velo-Gala I, López-Peñalver JJ, Sánchez-Polo M, Rivera-Utrilla $J$ (2014) Surface modifications of activated carbon by gamma irradiation. Carbon 67:236-249. https://doi.org/10.1016/j.carbo n.2013.09.087

44. Russo PA, Antunes MM, Neves P et al (2014) Solid acids with $\mathrm{SO}_{3} \mathrm{H}$ groups and tunable surface properties: versatile catalysts for biomass conversion. J Mater Chem A 2:11813-11824. https ://doi.org/10.1039/C4TA02320J

45. Xiang Q, Lee EE, Petterson PO, Torget RW (2003) Heterogeneous aspects of acid hydrolysis of a-cellulose. Appl Biochem Biotechnol 107:505-514

46. Huang L, Ye H, Wang S et al (2018) Enhanced hydrolysis of cellulose by highly dispersed sulfonated graphene oxide. BioResources 13:8853-8870

47. Gan L, Zhu J (2018) A ligning derived carbonaceous acid for efficient catalytic hydrolysis of cellulose. J Bioresour Bioprod 3:166-171. https://doi.org/10.21967/jbb.v3i4.9

48. Yuan S, Li T, Wang Y et al (2019) Double-adsorption functional carbon based solid acids derived from copyrolysis of PVC and PE for cellulose hydrolysis. Fuel 237:895-902. https://doi. org/10.1016/j.fuel.2018.10.088 
49. Li H-X, Zhang X, Wang Q et al (2018) Preparation of the recycled and regenerated mesocarbon microbeads-based solid acid and its catalytic behaviors for hydrolysis of cellulose. Bioresour Technol 270:166-171. https://doi.org/10.1016/j.biortech.2018.09.037

50. Chen G, Wang X, Jiang $Y$ et al (2019) Insights into deactivation mechanism of sulfonated carbonaceous solid acids probed by cellulose hydrolysis. Catal Today 319:25-30. https://doi. org/10.1016/j.cattod.2018.03.069

Publisher's Note Springer Nature remains neutral with regard to jurisdictional claims in published maps and institutional affiliations. 